\title{
De Garengeot hernisinin perfore apendisit ile birlikteliği: Nadir bir olgu sunumu
}

\author{
De Garengeot hernia associated with perforated appendicitis: A rare case report
}

\author{
Türker Acehan ${ }^{1}$, Emin Köse ${ }^{1}$, İhsan Gündüz ${ }^{2}$, Fazıl Sağlam ${ }^{1}$
}

Öz

De Garengeot hernisi, 1731 yılında Fransız bir cerrah olan Rene Jacques Croissant de Garengeot tarafından femoral herni kesesi içinde apendiks vermiformisin olması şeklinde tanımlanmış bir herni şeklidir. Literatürde 100 'den az vaka bildirilmiştir. Genellikle operasyon esnasında tanı alan bu vakaların preoperatif olarak bilgisayarlı tomografi ile tanı alması literatürde daha da nadirdir. $\mathrm{Bu}$ makalede karın ağrısı ile acil servise başvurarak bilgisayarlı tomografi ile preoperatif olarak De Garengeot hernisi tanısı alan bir hastanın sunulması amaçlanmıştır. Laparaskopik yaklaşımla femoral kanalda perfore apandisit izlenmiş ve apendektomi uygulanmıştır. Cerrahi tedavi açısından apendiksin akut enflame olup olmamasına, perforasyon/apse varlığına, cerrahi yaklaşım yeri tercihine ve apendektomi ile fitık onarımının eş zamanlı olup olmamasına göre farklı tedavi seçenekleri mevcuttur. Bizim olgumuzda laparoskopik apendektomi yapılmış, herni onarımı ikinci bir operasyona bırakılarak apendektomi ile birlikte drenaj ile yetinilmiştir.

Anahtar Kelimeler: De Garengeot hernisi, Femoral herni, Apandisit

\section{Abstract}

De Garengeot hernia is defined as the presence of the appendix vermiformis in the femoral hernia sac by a French surgeon, Rene Jacques Croissant de Garengeot, in 1731 . In literature, there are less than 100 cases. This clinical entity is usually diagnosed peroperatively and it is rarely noticed preoperatively on tomography scan. In this paper, it was aimed to present a patient admitting the emergency service with abdominal pain, diagnosed as De Garengeot hernia with perforated appendicitis preoperatively and undergone laparoscopic appendectomy. Depending on the presence or absence of acute infection of the appendix vermiformis, presence of perforation / abcess, type of surgical approach and whether appendectomy and hernia repair are performed simultaneously or not, there are different treatment modalities. In our case, laparoscopic appendectomy with abscess drainage was performed and hernia repair is planned as a delayed secondary intervention.

Keywords: De Garengeot's hernia, Femoral hernia, Appendicitis

\section{Giriş}

De Garengeot hernisi 1731 yılında Fransız bir cerrah olan Rene Jacques Croissant de Garengeot tarafından femoral herni kesesi içinde apendiksin olması şeklinde tanımlanmış herni şeklidir. Literatürde 100'den az vaka bildirilmiştir [1]. Tüm femoral hernilerin \% 0,5-5'ini oluşturur. Bu herni şeklinin akut apandisit hali ile başvurma insidansı ise \%0,08-0,13 olarak bildirilmektedir [2]. Böyle bir vaka ise ilk kez 1785 yılında Hevin tarafından bildirilmiştir. Yayınlanan literatürlere bakıldığında kadın/erkek oranı femoral hernilerin kadınlarda daha sık görülmesine paralel olarak 13/1 olarak rapor edilmektedir [2]. Genellikle operasyon esnasında tanı alan bu klinik durumun bilgisayarlı tomografi ile görüntülenmesine literatürde çok az rastlanmaktadır [3].

$\mathrm{Bu}$ makalede karın ağrısı ile acil servise başvurarak bilgisayarlı tomografi ile preoperatif olarak De Garengeot hernisi tanısı alan bir hastanın tedavi seçeneği ile birlikte sunulması amaçlanmıştır.
${ }^{1}$ Sağlık Bilimleri Üniversitesi, Okmeydan Eğitim ve Araştırma Hastanesi, Genel Cerrahi Kliniği, İstanbul, Türkiye.

${ }^{2}$ Mersin Üniversitesi, Tıp Fakültesi Hastanesi, Gastroenterolojik Cerrahi Kliniği, Mersin, Türkiye.

Bu çalışma 28 Ekim - 1 Kasım 2015, Antalya'da düzenlenen 10. Ulusal Travma ve Acil Cerrahi Kongresi'nde bildiri olarak sunulmuștur.

This study had been presented in 10th National Trauma and Emergency Surgery Congress, 28 October - 1 November 2015, Antalya, Turkey.

Çıkar Çatı̧ması: Yazarlar çıkar çatı̧ması bildirmemişlerdir.

Conflict of Interest: No conflict of interest was declared by the authors.

Finansal Destek: Yazarlar bu olgu için finansal destek almadıklarını beyan etmiş̧lerdir.

Financial Disclosure: The authors declared that this case has received no financial support.

Geliş Tarihi / Received

14.03.2017

Kabul Tarihi / Accepted 22.03.2017

Yayın Tarihi / Published

17.04.2017

Sorumlu yazar / Corresponding author

Türker Acehan

Adres: Sağlık Bilimleri Üniversitesi, Okmeydanı Eğitim

ve Araştırma Hastanesi, Genel Cerrahi Kliniği,

Kaptanpaşa Mh. Darulaceze Cad. Şişli, İstanbul,

Türkiye.

Tel: +905323006037

E-posta: dr-acehan@hotmail.com

Copyright 2017 ACEM 


\section{Olgu sunumu}

Hastadan olgu sunumunun hazırlanması ile ilgili yazılı onam alınmıştır.78 yaşında kadın hasta iki gündür olan karın ağrısı, bulantı ve kusma şikayetleri ile acil servise getirildi. Koroner ve renal arter stent öyküsü dışında özgeçmişinde özellik yoktu. Fizik muayenede inkarsere sağ femoral herni lehine değerlendirilen şişliğin yıllardır olduğunu belirten hastada akut batın bulguları mevcuttu. Laboratuar değerlerinde lökositoz ve CRP yüksekliği dışında anormal bulgu yoktu. Mevcut periferik arter hastalık anamnezi, klinik bulguları ve yaşı nedeniyle hastada ön planda akut mezenterik iskemi düşünülerek akut batın ayırıcı tanısı yapılmak amacıyla batın bilgisayarlı tomografik (BT) anjiyografi çekilmesi planlandi. Çekilen BT anjiyografide mezenterik arterler açık izlendi ancak sağ femoral kanal içinde apendiks vermiformisin bulunduğu ve periapendiküler dokuların enflame olduğu görülerek akut apandisit olarak değerlendirildi ve hasta acil operasyona alındı (Resim 1). Apendiks vermiformis preoperatif BT görüntüsü ile uyumlu şekilde sağ femoral kanal içinde yer almakta idi (Resim 2). Batın içinde ek patoloji gözlenmedi. Laparoskopik esnasında, organ herni kesesinden çıkarıldığında yer nekrotik alanlar nedeniyle perfore olduğu, periapendiküler alanda pü kollesiyonunun bulunduğu ve bunun herni kesesinden drene olduğu görüldü. Laparoskopik apendektomi yapıldı. Herni kesesi içerisinde püy olması sebebiyle greft kullanılmasının uygun olmadığı düşünülerek herni onarımı ikinci bir operasyona ertelendi. 3 günlük yatarak tedavi sonrası şifa ile taburcu edilen hastanın apendiks vermiformis patolojisi perfore apandisit olarak rapor edildi.

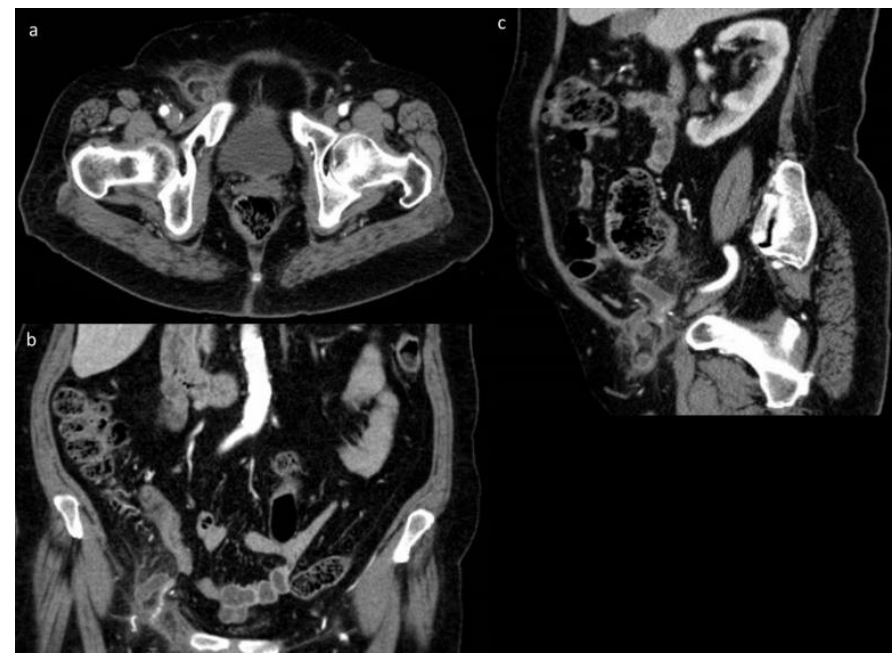

Resim 1: Batın BT kesitlerinde sağ femoral kanala girmiş apendiks vermiformis. Periapendiküler alanda enflamatuar değişiklikler.

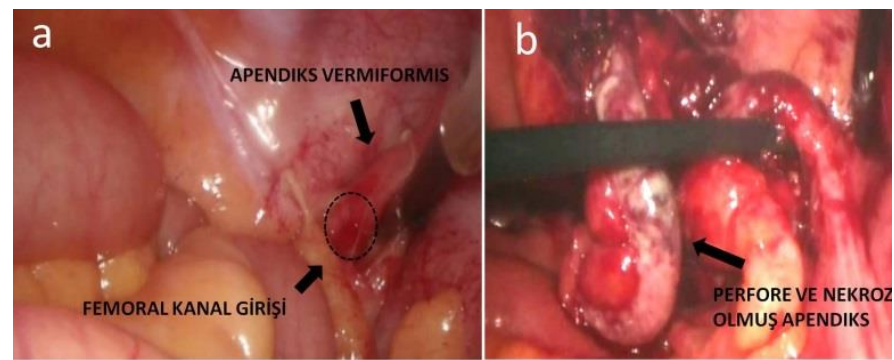

Resim 2 : a: Sağ femoral kanala girmiş apendiks vermiformisin laparoskopik görüntüsü. b: Femoral kanaldan çıkarılan enflame ve yer yer nekroze apendiks vermiformis.

\section{Tartışma}

Femoral herni kadınlarda daha sık görülür. Bu artmış prevalans gebelikteki değişimler ve sigara içimi, batın içi basınç artışı ya da kollajen defektleri gibi diğer risk faktörlerine bağlı olabilir. Femoral herni genellikle sağ tarafta görülmekle beraber herni kesesi içinde apendiks vermiformisin olması nadir bir durum olup, sıklıkla operasyon esnasinda tanı alır. Apendiksin femoral herni kesesinde yer alması ile ilgili iki teori mevcuttur. Birincisine göre geniş çekum varlığı apendiks vermiformisi aşağı doğru yer değiştirmeye zorlamaktadır.İkincisine göre ise anormal bir intestinal rotasyon ve çekal bağ mevcuttur [4]. Preoperatif tanısı zordur. Radyolojik bulgular genellikle nonspesifiktir. Buna karşın, bizim olgumuzda preoperatif BT ile tanı konulmuştur.

De Garengeot hernisi tedavisi için muhtemelen çok nadir görülmesinden dolayı henüz standart bir yaklaşım yoktur. Ancak enflame olsun ya da olmasın bu tip fitıklarda apendektomi önerilmektedir. İnkarsere femoral herni tespit edildiğinde ivedilikle ameliyat edilmesi gereklidir. Apse ya da perforasyon varlığ 1 yok ise prolen greft ile onarımı en çok kabul gören yaklaşımdır [5]. Apse varlığında ise greftin enfekte olmaması için Cooper ligament onarımı yapılması tercih edilmelidir. Diğer tedavi seçenekleri arasında drenaj ile birlikte geç apendektomi de bildirilmiştir. Bizim olgumuzda ise laparoskopik apendektomi yapılmış, herni onarımı ikinci bir operasyona birakılarak apendektomi ile birlikte drenaj ile yetinilmiştir. Postoperatif en çok bildirilen komplikasyon yara yeri enfeksiyonu olmakla birlikte, bizim olgumuzda herhangi bir komplikasyon gelişmemiştir.

Olgumuz literatürde bildirilen ilk De Garengeot hernisi vakası olmasa da uzun yıllar bu şekilde sessiz kalıp sonra perfore apandisit ile başvurma kliniği çok nadirdir. Literatürde benzer bir vaka bildirilmişse de, ilgili yazıda apendiks patolojik olarak değerlendirilmemiştir [5].

İnkarsere femoral herni içinde apendiks vermiformis bulunması çok sık karşılaşılan bir durum olmamakla birlikte, karşılaşıldığında acilen ameliyat edilmelidir.

\section{Kaynakça}

1. Talini C, Oliveira LO, Araújo AC, Netto FA, Westphalen AP. De Garengeot hernia: Case report and review. Int J Surg Case Rep 2015; 8: 35-7.

2. Al-Subaie S, Mustafa H, Al-Sharqawi N, Al-Haddad M, Othman F. A case of de Garengeot hernia: the feasibility of laparoscopic transabdominal preperitoneal hernia repair. Int J Surg Case Rep 2015; 16: 73-6.

3. Ahmed K, Bashar K, McHugh TJ, McHugh SM, Kavanagh E. Appendicitis in De Garengeot's Hernia Presenting as a Nontender Inguinal Mass: Case Report and Review of the Literature. Case Rep Surg 2014; 2014: 932638.

4. Whitehead-Clarke T, Parampalli U, Bhardwaj R. Incidental De Garengeot's hernia: A case report of dual pathology to remember. Int J Surg Case Rep 2015; 17: 39-41.

5. Schäfer HM, Holzen UV, Nebiker C. Swelling of the right thigh for over 30 years - The rare finding of a De Garengeot hernia. Int J Surg Case Rep 2014; 5: 1120-2. 